\section{Risk scoring systems to predict in-hospital mortality in patients with acute variceal bleeding due to hepatitis C virus- induced liver cirrhosis}

\author{
Moataz Hassanien, ${ }^{1}$ \\ Maged EL-Ghannam, ${ }^{1}$ \\ Mohamed Darwish EL-Talkawy, ${ }^{1}$ \\ Yosry Abdelrahman, ${ }^{1}$ Gamal El Attar, \\ Hoda Abu Taleb ${ }^{2}$ \\ ${ }^{1}$ Department of Hepatogastroenterology; \\ ${ }^{2}$ Biostatistics and Demography, Medical \\ Statistician, Department of Environment \\ Research, Theodor Bilharz Research \\ Institute, Giza, Egypt
}

\section{Abstract \\ This study was designed to validate and} to compare accuracy of the prognostic scores; mainly Child Turcotte Pugh (CTP), creatinine-modified Child Turcotte Pugh (CTP-Cr), model for end-stage liver disease (MELD), albumin bilirubin score (ALBI), and AIMS65, for the predicting clinical outcomes in cirrhotic Egyptian patients presenting with acute variceal bleeding (AVB). Retrospective single center study involving 725 patients presenting with AVB due to liver cirrhosis and $\mathrm{HCV}$ infection either alone or mixed with HBV infection. In hospital mortality prognostic scores were calculated; mainly CTP, modified CTP-Cr, MELD, ALBI, AIMS65. The endpoint is either patient improvement or death. 725 patients were included over 1-year period. $547(75 \%)$ survived and $178(25 \%)$ died. Patients presented with hematemesis $(515 / 71 \%)$, melena $(120 / 16.5 \%)$ or hematemesis and melena (90/12.5\%). Those with hematemesis for the first time were $241(33 \%)$ and recurrent attacks were 484 (66.8\%). The non-survivors had significantly more incidence of shock on presentation, more blood transfused units, history of NSAIDS intake, more ICU admission days and were more likely to be Childs C. Child, modified CTP-Cr, MELD, ALBI and ALMS65 scoring systems showed significant difference between survivors and nonsurvivors. Liver specific scores (Child, MELD) and gastrointestinal bleeding scoring systems (ALBI, AIMS65) are useful in predicting clinical outcomes of AVB in cirrhotic patients. CTP-Cr score had the highest prognostic capability of in hospital mortality. Presence of active bleeding at time of endoscopy, more complications, old age, shock and higher CPT-Cr score are addi- tional independent predictors of in hospital mortality.

\section{Introduction}

Acute variceal bleeding (AVB) is one of the most dreadful complications of liver cirrhosis that occurs in $20-50 \%$ of patients. Despite the improvements in prognosis in the past decade, the mortality of patients with AVB remains high (24\%) in cirrhotic patients. ${ }^{1}$ In Egypt, the commonest cause of upper GIT bleeding is bleeding esophageal varices due to liver cirrhosis either bilharzial and/or hepatitis $\mathrm{C} ;(51.6 \%) .{ }^{2,3}$

Estimation of prognosis is an essential element of managing patients with cirrhosis admitted to a hospital. Patients with cirrhosis and GI bleeding are classified as stage IV in Baveno IV consensus; with 1-year mortality risk of $57 \% .{ }^{4}$ Moreover, half of these patients will die within the 6 weeks after their admission for GI bleeding. ${ }^{5}$ Although several risk-stratification tools have been formulated, ${ }^{5-7}$ accurate stratification model to estimate in-hospital mortality (IHM), in cirrhotics admitted with acute upper GI bleeding is not currently available.

Many prognostic models for liver disease have been developed..$^{8} 9$ When cirrhotic patients are admitted to an ICU, the use of liver prognostic models, such as the Child Turcotte Pugh (CTP) and/or model for end-stage liver disease (MELD) scores, were found to be poor predictors of outcome. However, in patients with AVB, it still remains unclear if these models could do well in determining risk stratification among this group of patients. ${ }^{10}$

Modified CTP score was achieved by including creatinine into the score. The first analysis of creatinine-modified Child Turcotte Pugh (CTP-Cr) score was performed in 2003 by Angemayr. ${ }^{11}$ Recent studies quite clearly confirm that creatinine modified CTP score contributed to improvement of the initial CTP score in assessment of survival. ${ }^{12}$

Albumin-bilirubin (ALBI) score is initially created to assess the severity of liver dysfunction in Japanese patients with hepatocellular carcinoma (HCC). ${ }^{13}$ It is superior to Child-Pugh and MELD scores for predicting the occurrence of hepatic events in patients with primary biliary cholangitis. ${ }^{14}$ The prognostic performance of the ALBI score was comparable with that of the CTP and MELD scores for predicting the IHM of AUGIB in liver cirrhosis. ${ }^{15}$

The AIMS65 score was retrospectively validated in 32,507 patients. ${ }^{16}$ It was developed to predict IHM in acute upper GI
Correspondence: Maged EL-Ghannam, Department of Hepatogastroenterology, Theodor Bilharz Research Institute, Warrak El-Hadar 12411, Giza, Egypt.

E-mail: m.elghannam@tbri.gov.eg

Key words: Liver cirrhosis; Acute variceal bleeding; In hospital mortality; Creatininemodified child; Model for end-stage liver disease; albumin-bilirubin; ALMS65.

Contributions: MH, GEL, YA: conception and design; HAT: administrative support; MEG, MD: provision of study material or patients; MD: collection and assembly of data; HAT: data analysis and interpretation; all authors: manuscript writing and final approval of manuscript.

Conflict of interest: the authors declare no potential conflict of interest.

Funding: none.

Received for publication: 2 February 2018. Accepted for publication: 12 March 2018.

This work is licensed under a Creative Commons Attribution NonCommercial 4.0 License (CC BY-NC 4.0).

(C) Copyright M. Hassanien et al., 2018 Licensee PAGEPress, Italy

Gastroenterology Insights 2018; 9:7629 doi:10.4081/gi.2018.7629

bleeding. These score uses only 5 elements that contribute equally to the score for ease of use and calculation. When more than two components of AIMS65 are present, the mortality risk is considered to be high.

The aim of this study is to validate and compare the accuracy of prognostic scores; mainly CTP, CTP-Cr, MELD, ALBI, and AIMS65, in predicting clinical outcomes in cirrhotic Egyptian patients presenting with AVB.

\section{Materials and Methods}

This is a retrospective cohort study that includes all adult cirrhotic patients presenting with AVB (hematemesis, melena and /or bloody fluids either as vomitus or drained by nasogastric tube) admitted to the ICU of Tropical Medicine Department in Theodor Bilharz Research Institute Hospital over one-year period from $1 / 2016$ to $1 / 2017$.

The ethical approval was obtained from the Ethical Committee Board of our hospital. Due to the retrospective nature of our study, the written informed consents were exempted. 


\section{Inclusion criteria}

All Cirrhotic patients presented by bleeding varices (esophageal, fundal or both).

\section{Exclusion criteria}

Patients with other causes of upper GIT bleeding (such as: peptic ulcer disease, reflux esophagitis, erosions, antral vascular ectasia) previously or at endoscopy after admission.

A complete history, thorough physical examination, monitoring of vital signs, to all patients were recorded. Liver function and serum creatinine were assessed on admission and serially during hospitalization. Complete blood count, serum electrolytes, arterial blood gases, and number of units of blood received were recorded. All patients underwent abdominal ultrasonography and testing for HBsAg and anti-HCV.

All patients underwent upper endoscopy and therapy was initiated according to the endoscopic findings, all the endoscopic findings were described according to the Japanese research society for portal hypertension. ${ }^{17}$

All prognostic scores were calculated from the data collected on the 1st day of admission namely CTP, MELD, iMELD, United Kingdom Model for End Stage Liver Disease (UKELD), Updated MELD score, CTP-Cr, AIMS65 and ALBI scores.

\section{Calculation of scores}

1-CTP score (calculated according to the Pugh modification $)^{8}$

2-ALBI score $=(\log 10$ bilirubin $\times 0.66)+$ (albumin $\times-0.085$ ).

In this equation, the unit of bilirubin is umol/L and that of albumin is $\mathrm{g} / \mathrm{L}$.

ALBI was classified into three grades: grade 1: $\leq-2.6$; grade $2:>-2.6, \leq-1.39$; grade 3: $>-1.39^{13}$

3-MELD score $=\{9.57 \times \ln$ [creatinine $(\mathrm{mg} / \mathrm{dL})]+3.78 \times \ln [$ bilirubin $(\mathrm{mg} / \mathrm{dL})]+$ $11.2 \times \ln (\mathrm{INR})+6.43\} ; 9$

4 -iMELD score $=\{$ MELD + age (in years $)$ $\times 0,3)-[0,7 \times \mathrm{Na}(\mathrm{mmol} / \mathrm{L})]+100\}^{18}$

5 -UKELD score $=\{5 \times[1.5 \times \ln (\mathrm{INR})+$ $0.3 \times \ln ($ creatinine $(\mu \mathrm{mol} / \mathrm{L})]+0.6 \times \ln$ [bilirubin $(\mu \mathrm{mol} / \mathrm{L})-13 \times \ln (\mathrm{Na}(\mathrm{mmol} / \mathrm{L})$ $+70]\}^{19}$

6-Updated MELD score $=\{[1.27 \times \ln (1+$ creatinine $(\mathrm{mg} / \mathrm{dL})]+0.94 \times \ln [1+$ biliru$\operatorname{bin}(\mathrm{mg} / \mathrm{dL})]+1.66 \times \ln (1+\mathrm{INR})]\}^{20}$

7-AIMS65 score calculated according to Saltzman et al. ${ }^{16}$ i) Alb (mg/dL): < $3.0(1$ point); ii) INR > $1.5 \mathrm{~s}$ (1 point); iii) HE: < 14 (1 point); iv) Shock: < 90 (1 point); v) Age $>65$ years (1 point).

8-CTP-Cr scores (numerical values 5-19) includes three categories as follow: 0 points are added to patients whose serum creati-
Table 1. Demographic and clinical data of survivors and non- survivors.

\begin{tabular}{lccc} 
Variables & $\begin{array}{c}\text { Survivor } \\
\text { N=547(75.4\%) }\end{array}$ & $\begin{array}{c}\text { Non survivor } \\
\text { Ne178(24.6\%) }\end{array}$ & P-value \\
Age, (yrs) & $57.59 \pm 0.46$ & $58.14 \pm 0.87$ & 0.351 \\
$>65$ & $72.19 \pm 0.55$ & $71.16 \pm 0.88$ & 0.521 \\
\hline$<65$ & $53.13 \pm 0.36$ & $52.32 \pm 0.73$ & \\
Male & $413(75.5 \%)$ & $87(48.90 \%)$ & $<0.01$ \\
\hline Female & $134(24.49 \%)$ & $91(51.10 \%)$ & \\
HCV (n,\%) & $547(100 \%)$ & $178(100 \%)$ & \\
\hline HBV+HCV (n,\%) & $3(0.54 \%)$ & $20(11.24 \%)^{* *}$ & $<0.01$ \\
Hematemesis (n,\%) & $392(71.66 \%)$ & $123(69.10 \%)$ & 0.575 \\
\hline Melena (n,\%) & $84(15.36 \%)$ & $36(20.22 \%)$ & 0.160 \\
Hematemesis + Melena (n,\%) & $71(12.97 \%)$ & $19(10.67 \%)$ & 0.496 \\
\hline st Attack of hematemesis (n,\%) & $195(35.65 \%)$ & $46(25.84 \%) b$ & $<0.05$ \\
Recurrent attacks of hematemesis (n,\%) & $352(64.35 \%)$ & $132(74.16 \%)^{*}$ & $<0.05$ \\
\hline Shock (n,\%) & $97(17.73 \%)$ & $111(62.36 \%)^{* *}$ & $<0.01$ \\
PRBC Transfused (\%) & $130(23.76 \%)$ & $170(95.51 \%)$ & $<0.01$ \\
\hline Child A (n,\%) & $67(12.25 \%)$ & $29(16.29 \%)$ & 0.209 \\
Child B (n,\%) & $220(40.22 \%)$ & $30(16.85 \%)^{* * *}$ & $<0.05$ \\
\hline Child C (n,\%) & $260(47.53 \%)$ & $119(66.85 \%)^{* *}$ & $<0.01$ \\
ICU Admission Days & $1.74 \pm 0.07$ & $2.06 \pm 0.05 *$ & $<0.05$ \\
\hline NSAIDs (n,\%) & $63(11.52 \%)$ & $52(29.21 \%)^{* *}$ & $<0.01$ \\
\hline
\end{tabular}

Data were represented as Mean $\pm \mathrm{SE}$; Man Whitney test (U-test); Chi square test $\left(\chi^{2}\right)$. HBV: hepatitis B virus; HCV: hepatitis C virus. ${ }^{*} \mathrm{P}<0.05$; $* \mathrm{P}<0.01$ significant increase than survivor; ${ }^{* *} \mathrm{P}<0.05$ significant decrease than survivor.

Table 2. Laboratory data of survivors and non-survivors.

\begin{tabular}{lccc} 
Variables & $\begin{array}{c}\text { Survivor } \\
\text { N=547 }\end{array}$ & $\begin{array}{c}\text { Non survivor } \\
\text { N=178 }\end{array}$ & P-value \\
WBC $\left(x 10^{9} / \mathrm{L}\right)$ & $10.42 \pm 0.45$ & $12.26 \pm 0.63^{*}$ & $<0.03$ \\
Hemoglobin $(\mathrm{g} / \mathrm{dL})$ & $9.27 \pm 0.29$ & $8.76 \pm 0.16$ & 0.291 \\
\hline Platelets $\left(x 10^{9} / \mathrm{L}\right)$ & $127.87 \pm 4.36$ & $117.92 \pm 5.38$ & 0.228 \\
Sodium $(\mathrm{mmol} / \mathrm{L})$ & $134.98 \pm 0.34$ & $125.18 \pm 2.06^{\mathrm{a}}$ & $<0.01$ \\
\hline Creatinine $(\mathrm{mg} / \mathrm{dL})$ & $3.90 \pm 0.16$ & $4.88 \pm 0.32^{* *}$ & $<0.01$ \\
PT(s) & $12.03 \pm 0.62$ & $15.01 \pm 0.90^{* *}$ & $<0.01$ \\
\hline INR (seconds) & $1.61 \pm 0.05$ & $1.81 \pm 0.04^{*}$ & $<0.02$ \\
Total bilirubin (umol/dL) & $3.99 \pm 0.32$ & $4.88 \pm 0.32^{* *}$ & $<0.01$ \\
\hline ALB (umol/L) & $2.92 \pm 0.05$ & $2.66 \pm 0.05^{\mathrm{b}}$ & $<0.05$ \\
ALT (U/L) & $62.44 \pm 3.97$ & $62.81 \pm 5.87$ & $>0.62$ \\
\hline AST (U/L) & $84.18 \pm 6.48$ & $90.76 \pm 17.72$ & $>0.96$ \\
\hline
\end{tabular}

Values are presented as number (\%) or mean \pm SE. HE: hepatic encephalopathy; WBC: white blood cell; Hb: hemoglobin; PLT: platelet; TBIL: total bilirubin; ALB: albumin; ALT: alanine aminotransferase; AST: aspartate aminotransferase; Cr: creatinine; PT: prothrombin time; INR: international normalized ratio. ${ }^{*} \mathrm{P}<0.05$ significant increase; ${ }^{*} \mathrm{P}<0.001$ significant increase; ${ }^{\mathrm{a}} \mathrm{P}<0.01$ significant decrease; ${ }^{\mathrm{b}}<0.05$ significant decrease.

Table 3. Comorbid diseases in all patients.

\begin{tabular}{|c|c|c|c|}
\hline Variables & $\begin{array}{c}\text { Survivor } \\
\mathrm{N}=547\end{array}$ & $\begin{array}{c}\text { Non survivor } \\
\mathrm{N}=178\end{array}$ & P-value \\
\hline Hypertension (n,\%) & $94(17.18 \%)$ & $75(42.13 \%)^{* *}$ & $<0.01$ \\
\hline Diabetes mellitus (n,\%) & $153(28.0 \%)$ & $90(50.56 \%)^{* *}$ & $<0.01$ \\
\hline Cardiovascular (n,\%) & $33(6.03 \%)$ & $20(11.24 \%)^{* *}$ & $<0.01$ \\
\hline CRF (n,\%) & $28(5.12 \%)$ & $12(6.7 \%)$ & 0.456 \\
\hline Chest infection (n,\%) & $5(0.91 \%)$ & $51(28.65 \%)^{* *}$ & $<0.01$ \\
\hline CNS (n,\%) & $14(2.6 \%)$ & $43(24.16 \%)^{* *}$ & $<0.01$ \\
\hline
\end{tabular}

**P<0.01 significant increase than survivor test of proportion. 
nine level does not exceed $1.3 \mathrm{mg} / \mathrm{dL}$ $(114.92 \mu \mathrm{mol} / \mathrm{L}) ; 2$ points are added to patients whose serum creatinine level is between 1.3-1,8 mg/dL (114.92-159.12 $\mu \mathrm{mol} / \mathrm{L}) ; 4$ points are added to patients whose serum creatinine level exceeds 1.8 $\mathrm{mg} / \mathrm{dL}(159.12 \mu \mathrm{mol} / \mathrm{L}) .{ }^{12}$

\section{Statistical analysis}

All statistical analyses were performed using the Med-Calc software version (11.4.2.0.). Continuous data were expressed as the mean \pm standard error (SE). Areas under the receiving-operator characteristics curves (AUC) with $95 \%$ confidence intervals (CIs) were calculated and compared among using the DeLong tests. Then, sensitivity, specificity, positive predictive value, and negative predictive value with $95 \%$ CIs were reported. Subgroup analyses were performed in patients with only hepatitis B or $\mathrm{C}$ virus-related liver cirrhosis and in those treated with endoscopic therapy for AUGIB. $\mathrm{P}<0.05$ was considered statistically significant.

The normality of data was tested by Kolmogorov-Smirnov test. For comparing two sets of data, in case of normal data distribution we used the $t$-test and if data distribution was not normal, the Mann-Whitney's $U$-tests; between the groups were compared by using the chi-square $\left(\chi^{2}\right)$ and test of proportion.

\section{Results}

A total of 725 patients (500 males and 225 females) were admitted to our department over a period of 1 year due to acute variceal bleeding. Their demographic and clinical data are shown in Table 1. Our endpoint is either patient improvement or transfer to the ward or patient death. 547 (75\%) survived and 178 (25\%) died. The etiology of liver cirrhosis was $\mathrm{HCV}$ in all patients $(100 \%)$, however, $23(3.2 \%)$ had in addition HBV infection. Survivors and those who died were similarly matched with regard to gender, age, ethnicity and etiology of cirrhosis. $515(71 \%)$ patients presented with hematemesis, $120(16.5 \%)$ presented with melena and $90(12.5 \%)$ presented with both hematemesis and melena. Those with hematemesis for the first time were 241 (33\%) and those with recurrent attacks were 484 (66.8\%). In our patients, all varices dealt with band ligation. The non-survivors had significantly more incidence of shock on presentation, more blood transfused units, more history of NSAIDS intake, and more ICU admission days. Non-survivors were more likely to be Childs C.

Table 2 showed laboratory data of both survivors and non-survivors. Non-survivors had higher white blood cell counts, lower platelets count, lower hemoglobin concentration, higher blood urea nitrogen, lower sodium, higher creatinine, higher INR, higher bilirubin and lower albumin.

Table 3 showed the comorbid conditions that were significantly higher in nonsurvivors compared to the survivors. 169 $(23 \%)$ patient had hypertension, 243 $(33.5 \%)$ were diabetics, $53(0.07 \%)$ had ischemic heart disease, $40(0.06 \%)$ patients had uremia. Complications of cirrhosis occurred more evident in non-survivors compared to the survivors Table 4. Endoscopic findings of survivors and nonsurvivors are showed in Table 5.
Different scoring systems had been shown in Table 6. CTP, CPT-Cr, MELD, ALBI and ALMS65 scoring systems showed significant difference between survivors and non-survivors. We analyzed the prognostic and risk stratification models for predicting in hospital mortality (Table 7). The CPT-Cr score had the largest AUROC, followed by Child-Pugh then the MELD score, all of which achieved good performance (AUROC $>0.82$ ). According to the logistic regression, factors giving the best model are complications ( $>4 \mathrm{D})$, age $(>65 \mathrm{Y})$, presence of active bleeding at endoscopy (Yes), shock (Yes), days ( $>2 \mathrm{~d}$ ), and CPT-Cr $(>2)$ (Table 8).

Table 4. Complication of cirrhosis in survivors and non-survivors.

\begin{tabular}{lccc} 
Variables & $\begin{array}{c}\text { Survivor } \\
\mathbf{N}=\mathbf{5 4 7}\end{array}$ & $\begin{array}{c}\text { Non survivor } \\
\mathbf{N}=\mathbf{1 7 8}\end{array}$ & $\begin{array}{c}\text { P-value } \\
\text { Ascites }\end{array}$ \\
Hepatic encephalopathy & $338(61.79 \%)$ & $163(91.57 \%)^{* *}$ & $<0.01$ \\
\hline SBP & $142(25.96 \%)$ & $99(55.62 \%)^{* *}$ & $<0.01$ \\
HRS & $25(4.5 \%)$ & $37(20.79 \%)^{* *}$ & $<0.01$ \\
Hepatocellular carcinoma (n,\%) & $51(9.32 \%)$ & $65(36.52 \%)^{* *}$ & $<0.01$ \\
PVT & $28(5.12 \%)$ & $61(34.26 \%)^{* *}$ & $<0.01$ \\
\hline
\end{tabular}

**P $<0.01$ significant increase than survivor; ${ }^{*}<0.05$ significant increase.

Table 5. Endoscopic finding of survivors and non-survivors.

\begin{tabular}{llccc} 
Variables & & $\begin{array}{c}\text { Survivor } \\
\text { N=547 }\end{array}$ & $\begin{array}{c}\text { Non survivor } \\
\text { N=178 }\end{array}$ & P-value \\
Esophageal Varices & GI & $84(15.36 \%)$ & $23(12.92 \%)$ & 0.454 \\
& GII & $106(19.38 \%)$ & $29(16.29 \%)$ & 0.412 \\
& GIII & $135(24.68 \%)$ & $34(19.10 \%)$ & 0.613 \\
& GIV & $163(29.80 \%)$ & $49(27.53 \%)$ & 0.840 \\
\multirow{5}{*}{ Stomach } & $59(10.79 \%)$ & $43(24.16 \%)^{* *}$ & 0.001 \\
& Eradicated & $252(46.07 \%)$ & $60(33.71 \%)^{\mathrm{a}}$ & 0.01 \\
& Gastric Varices & $88(16.09 \%)$ & $77(43.26 \%)^{* *}$ & 0.001 \\
& Portal hypertensive gastropathy & $205(37.48 \%)^{\mathrm{a}}$ & $29(16.29 \%)^{\mathrm{a}}$ & 0.001 \\
& Gastric Ulcer (GU) & $105(14.5 \%)$ & 0.07 \\
\hline
\end{tabular}

${ }^{* *} \mathrm{P}<0.001$ significant increase, ${ }^{\mathrm{P}}<0.01$ significant decrease than survivors.

Table 6. Different scoring systems in survivors and non- survivors.

\begin{tabular}{lccc} 
Model & $\begin{array}{c}\text { Survivor } \\
\mathbf{N}=547\end{array}$ & $\begin{array}{c}\text { Non survivor } \\
\mathbf{N}=178\end{array}$ & P-value \\
Child-Pugh score & $9.40 \pm 0.11$ & $10.19 \pm 0.22^{* * *}$ & $<0.001$ \\
CPT-Cr & $10.42 \pm 0.13$ & $11.10 \pm 0.24^{* *}$ & $<0.01$ \\
\hline MELD score & $16.47 \pm 0.38$ & $19.24 \pm 0.78^{* *}$ & $<0.01$ \\
iMELD score & $42.75 \pm 0.77$ & $46.47 \pm 1.62^{*}$ & $<0.05$ \\
\hline UKELD score & $10.37 \pm 0.26$ & $10.56 \pm 0.54$ & $>0.29$ \\
Updated MELD score & $2.73 \pm 0.06$ & $2.64 \pm 0.09$ & $>0.36$ \\
\hline AIMS65 & $2.82 \pm 1.46$ & $3.20 \pm 0.79$ & $>0.82$ \\
ALBI score & $0.04 \pm 0.01$ & $0.05 \pm 0.02$ & $>0.65$
\end{tabular}

CPT: CTP Creatinine (CTP-cr); MELD: Model for end-stage liver disease; ALBI: albumin-bilirubin; iMELD: Integrated score; UKELD: United Kingdom model for end stage liver disease. ${ }^{* * *} \mathrm{P}<0.001$ very highly significant increase than survivor; ${ }^{* *} \mathrm{P}<0.01$ highly significant increase than survivor. ${ }^{*} \mathrm{P}<0.05$ considered significant increase than survivor. 
dynamic instability, number of transfused blood units, days of ICU admission and history of NSAIDS intakes are factors denoting bad prognosis and increased mortality. In addition, elevated serum bilirubin, decrease serum albumin, prolonged prothrombin time, increase serum crearinine and decrease platelet count significantly affect the prognosis. This is in agreement with other reports. ${ }^{24,25}$

We have $25 \%$ IHM rate. In 1986 , Chojkier and colleagues ${ }^{25}$ reported a bleeding-related mortality rate of $35 \%$, whereas Afessa and Kubilis in the year $2000^{24}$ reported IHM rate of $21 \%$ in bleeding cirrhotics. More recently, Chalasani et al. ${ }^{26}$ in a large study over 3 years reported the IHM to be $14.2 \%$. Pauwels et al. ${ }^{27}$ showed that IHM in cirrhotic patients admitted with variceal bleeding has decreased by $50 \%$ over the past 15 years. This in contrary to other studies where the IHM rate $8.7 \%$ is consistent with the experience from other centers. ${ }^{28}$ Similar decline in the IHM rate has been reported in other studies. ${ }^{29}$ The variation of the IHM for cirrhotic patients with variceal hemorrhage is likely related to the degree of underlying liver dysfunction, the use of life support systems such as blood, vasoactive agents, and endotracheal intubation, and the subsequent development of clinical complications including renal insufficiency, cardiopulmonary complications, and infection. In our study, the high mortality rate could be explained as most of our patients had advanced liver disease as indicated by Child C grade; 379 (52\%) and $250(34.5 \%)$ patients were Child B. ${ }^{30}$

Although IHM in cirrhotic patients with GI bleeding is declining ${ }^{31,32}$ it is still associated with significant morbidity and mortality. ${ }^{26,28}$ More than half of patients with GI bleeding have a comorbid disease mainly hypertension, diabetes mellitus, coronary artery diseases, and malignancies. ${ }^{31}$ Clinical guidelines published in 2008 in Scotland cited a mortality rate of $4 \%$ in GI bleeding patients without comorbidities, with the mortality rate increasing 1.8 times in cases with heart failure, 3.8 times in cases with malignancy, and 2.0 times in cases with liver disease. ${ }^{32}$ According to the NIH 2012 guidelines, patients with GI bleeding who also have chronic diseases are at a higher risk of death; ${ }^{33}$ Patients with DM and $\mathrm{CAD}$, however, had significantly higher rates of ICU admission. Acute bleeding causes hemodynamic instability, and this condition worsens in the condition of CAD, particularly in patients with heart failure. Another factor underlying the higher ICU admission rate of patients with CAD was anticoagulant, antithrombotic and antiplatelet therapy. ${ }^{34}$

Our patients were found to have DM in $243(33.5 \%)$ patients; 153 (28\%) survivors and $90(50.5 \%)$ non-survivors with significantly high value. DM is associated with gastroesophageal variceal bleeding in cirrhotic and increased risk of IHM. The risk of bleeding increases in patients with poor glycemic control. ${ }^{35}$ The higher mortality rate in patients with diabetes is not only due to the complications of DM but also to an increased risk of hepatocellular failure in long-term follow up. ${ }^{36}$ Hyperglycemia induces splanchnic hyperemia, increases portal pressure and may increase the risk of variceal bleeding. ${ }^{37} \mathrm{DM}$, active bleeding at endoscopy and bilirubin $>3 \mathrm{mg} / \mathrm{dL}$ are bad prognostic factors for initial control of variceal bleeding, and recurrent bleeding in patients with cirrhosis. ${ }^{38}$

In a cohort study of patients with chronic hepatitis $\mathrm{C}$, new-onset diabetes subsequently were found to have an increased risk of developing cirrhosis, or decompensation in those with established cirrhosis. ${ }^{39}$ $\mathrm{HCV}$ is associated with extra-hepatic diseases, including various types of glomerulonephritis. Soma et al. ${ }^{40}$ indicated that $\mathrm{HCV}$ infection leads to a rapid decline in the renal function of patients with diabetic nephropathy.

Uremic bleeding is a well-recognized complication in patients with renal failure, and it affects platelet aggregation and/or the coagulation cascade. ${ }^{41}$ In patients with chronic kidney disease, GI bleeding is also a common complication. ${ }^{42}$ Anand et al. ${ }^{43}$

Table 7. Predictive value of different scoring models.

\begin{tabular}{|c|c|c|c|c|c|}
\hline Model & AUROC & Sensitivity & Specificity & CI $95 \%$ & P-value \\
\hline Child-Pugh score & $0.810 \pm 0.017$ & 90.48 & 67.68 & $0.777-0.843$ & $<0.001$ \\
\hline CPT-Cr & $0.826 \pm 0.018$ & 90.68 & 70.36 & $0.791-0.862$ & $<0.001$ \\
\hline MELD score & $0.692 \pm 0.023$ & 88.31 & 67.68 & $0.648-0.737$ & $<0.001$ \\
\hline iMELD score & $0.558 \pm 0.025$ & 70.36 & 74.59 & $0.509-0.608$ & $<0.01$ \\
\hline UKELD score & $0.479 \pm 0.025$ & 70.92 & 69.90 & $0.431-0.527$ & 0.386 \\
\hline Updated MELD score & $0.527 \pm 0.04$ & 73.21 & 65.91 & $0.449-0.605$ & 0.513 \\
\hline AIMS65 & $0.525 \pm 0.024$ & 63.97 & 69.75 & $0.478-0.572$ & 0.309 \\
\hline ALBI score & $0.539 \pm 0.03$ & 71.20 & 67.37 & $0.466-0.612$ & 0.338 \\
\hline
\end{tabular}


showed that elevated serum creatinine levels are associated with increased rates of mortality and re-bleeding.

We check the performance of 8 prognostic scoring systems in cirrhotic patients with AVB. All of them showed good prognostic capability and can discriminate between survivors and non-survivors with AUC above 0.82. CTP-Cr score had the highest prognostic capability followed by CTP scores. Our results are in contrary with, Al-Freah et al. ${ }^{44}$ who found that MELD had the best performance as the best liver prognostic model but did not significantly differ from other ICU scoring models as predictors of outcome. Peng et al. in $2015^{45}$ found that both scoring systems; CTP and MELD, had good discriminative abilities for the IHM of acute UGIB in liver cirrhosis, and that the AUROC for MELD score might be slightly superior to that for Child-Pugh score, but with no statistically significant difference.

The significance of MELD score in predicting short-term survival is more superior to CTP score both in short and long-term (12-month and 36-month). The highest difference in the compared scores (CTP and MELD) is present in 6-week and 3-month periods of follow-up where MELD score is dominant. Although the difference is still on the side of MELD score, it is lower in 12month and 36-month periods of followup. ${ }^{46}$

Patients with bleeding from esophageal varices who have CTP score and CTP-cr I score higher than 10.5 and CTP-cr II score higher than 11.5 , have statistically significantly higher risk from mortality within one-month follow-up compared to patients with bleeding from esophageal varices who have lower numerical values of scores of the CTP group. ${ }^{12}$

Contrary to our results, Nakamura et al. found that the AIMS65 score is the best for predicting mortality among the mentioned five scores. It was previously reported to be a good predictor of the outcome of patients with acute upper gastrointestinal hemor- rhage. ${ }^{47}$ Moreover, Hyett et al. ${ }^{48}$ found that the AIMS65 score was better than the Glasgow-Blatchford score for outcome prediction in those patients. Motola-Kuba et al. in $2016^{21}$ found no differences in the accuracy between MELD and AIMS65 for predicting IHM, both of them with good calibration.

The more incidence of the complications; namely, SBP, hepatic encephalopathy, HCC, PVT, HR syndrome, the more worse the prognosis. This is in agreement with previous report. ${ }^{49}$

Our study has limitations. It was a retrospective design, the accuracy is just enough only to predict IHM, more data is necessary for other outcomes. Being a single-center observational study, confounding factors were relatively difficult to avoid. With the limitation of sample size and the relatively short follow-up period, additional well designed prospective studies with larger sample sizes are required. Our study was performed at a large urban hospital that may not be representative of the demographics of the other groups, and thus could potentially limit the generalizability of the study. Our study was also performed at a singlesite, and thus biases in the severity of clinical disease, or the nature of clinical practice at this institution could be present. However, we suspect this to be unlikely, as outcomes were consistent with other published studies.

\section{Conclusions}

Liver specific scores (Child, MELD) and gastrointestinal bleeding scoring systems (ALBI, AIMS65) are useful in predicting clinical outcomes of AVB in cirrhotic patients. CTP-Cr score had the highest prognostic capability of in hospital mortality. Presence of active bleeding at time of endoscopy, more complications, old age, shock and higher CPT-Cr score are additional independent predictors of in hospital mortality.

Table 8. Logistic regression analysis of factors effecting mortality.

\begin{tabular}{lcccc} 
Variable* & $\beta * *$ & OR & CI (OR) & P-value \\
Age & 0.429 & 1.536 & $1.270-1.857$ & $<0.000$ \\
Complications & 0.936 & 2.551 & $1.532-4.246$ & $<0.000$ \\
\hline Shock & -2.273 & 0.103 & $0.067-0.158$ & $<0.000$ \\
Days & -0.163 & 0.849 & $0.736-0.980$ & $<0.05$ \\
\hline CPT-Cr & 2.039 & 0.848 & $0.734-0.981$ & $<0.003$ \\
Bleeding & 0.512 & 1.619 & $1.101-2.607$ & $<0.01$
\end{tabular}

Factors giving the best model are complications ( $>4 \mathrm{D})$, age ( $>65 \mathrm{Y}$ ), presence of active bleeding at endoscopy, shock, days $(>2 \mathrm{~d})$, and CPT$\operatorname{Cr}(>2)$.

\section{References}

1. Amitrano L, Guardascione MA, Manguso F, et al. The effectiveness of current acute variceal bleed treatments in unselected cirrhotic patients: refining short-term prognosis and risk factors. Am J Gastroenterol 2012;107:1872-8.

2. Elwakil R, Reda M, Abdelhakam S, et al. Causes and outcome of upper gastrointestinal bleeding in Emergency Endoscopy Unit of Ain Shams University Hospital. Egyptian Soc Parasitol 2013;41:455-67.

3. Taha M, Saad S, Elbaih A, et al. Risk stratification and outcome in haematemesis patients in emergency room in Suez Canal university hospital, Ismailia, Egypt. Int Surg J 2016;3:124955.

4. de Franchis R. Evolving consensus in portal hypertension. Report of the Baveno IV consensus workshop on methodology of diagnosis and therapy in portal hypertension. J Hepatol 2005;43:167-76.

5. Lecleire S, Di Fiore F, Merle V, et al. Acute upper gastrointestinal bleeding in patients with liver cirrhosis and in noncirrhotic patients: epidemiology and predictive factors of mortality in a prospective multicenter population-based study. J Clin Gastroenterol 2005;39:321-7.

6. D'Amico G, De Franchis R. Upper digestive bleeding in cirrhosis. Posttherapeutic outcome and prognostic indicators. Hepatology 2003;38:599612.

7. Hsu YC, Liou JM, Chung CS, et al. Early risk stratification with simple clinical parameters for cirrhotic patients with acute upper gastrointestinal bleeding. Am J Emerg Med 2010;28:88490.

8. Pugh RN, Murray-Lyon IM, Dawson JL, et al. Transection of the oesophagus for bleeding oesophageal varices. $\mathrm{Br} \mathrm{J}$ Surg 1973;60:646-9.

9. Wiesner R, Edwards E, Freeman R, et al. Model for end-stage liver disease (MELD) and allocation of donor livers. Gastroenterology 2003;124:91-6.

10. Mohammad A, Morsy K. Variceal bleeding in cirrhotic patients: What is the best prognostic score? Turk J Gastroenterol 2016;27:464-9.

11. Angermayr B. Child-Pugh versus MELD score in predicting survival in patients undergoing transjugular intrahepatic portosystemic shunt. Gut 2003;52:879-85.

12. Radisavljević M, Bjelaković G, Jović J, et al. Creatinine-modified Child- 
Turcotte-Pugh score is a good predictor of a short-term survival in patients with bleeding from esophageal varices. Vojnosanit Pregl 2017;74:13-8.

13. Johnson PJ, Berhane S, Kagebayashi C, et al. Assessment of liver function in patients with hepatocellular carcinoma: a new evidence-based approach-the ALBI grade. J Clin Oncol 2015;33:550-8.

14. Chan AW, Chan RC, Wong GL, et al. New simple prognostic score for primary biliary cirrhosis: Albumin-bilirubin score. J Gastroenterol Hepatol 2015;30:1391-6.

15. Zou D1, Qi X, Zhu C, et al. Albumin-bilirubin score for predicting the in-hospital mortality of acute upper gastrointestinal bleeding in liver cirrhosis: A retrospective study. Turk J Gastroenterol 2016;27:180-6.

16. Saltzman JR, Tabak YP, Hyett BH, et al. A simple risk score accurately predicts in-hospital mortality, length of stay, and cost in acute upper GI bleeding. Gastrointestinal Endosc 2011;74:121524.

17. Ogihara T, Kikuchi K, Matsuoka H, et al. The Japanese Society of Hypertension guidelines for the management of hypertension (JSH 2009). Hypertens Res 2009;32:3-107.

18. Luca A, Angermayr B, Bertolini G, et al. An integrated MELD model including serum sodium and age improves the prediction of early mortality in patients with cirrhosis. Liver Transpl 2007;13:117480.

19. Barber K, Pioli S, Blackwell J. Development of a UK score for patients with end-stage liver disease. Hepatology 2007;46:510A.

20. Sharma P, Schaubel DE, Sima CS, et al. Re-weighting the model for end-stage liver disease score components. Gastroenterology 2008;135:1575-81.

21. Motola-Kuba M, Escobedo-Arzate A, Tellez-Avila F, et al. Validation of prognostic scores for clinical outcomes in cirrhotic patients with acute variceal bleeding. Ann Hepatol 2016;15:895-901.

22. Özlem K, Özeren G, Özdem F, et al. Prospective validation of the Glasgow Blatchford scoring system in patients with upper gastrointestinal bleeding in the emergency department. Turk J Gastroenterol 2012;23:448-55.

23. Chaikitamnuaychoka R, Patumanondb J. Clinical risk characteristics of upper gastrointestinal hemorrhage severity: a multivariable risk analysis. Gastroenterol Res 2012;5:149-55.

24. Afessa B, Kubilis PS. Upper gastrointestinal bleeding in patients with hepatic cirrhosis: clinical course and mortality pre- diction. Am J Gastroenterol 2000;95:4849.

25. Chojkier M, Laine L, Conn HO, Lerner E. Predictors of outcome in massive upper gastrointestinal hemorrhage. J Clin Gastroenterol 1986;8:16-22.

26. Chalsani N, Kahi C, Francois F, et al. Improved patient survival after acute variceal bleeding: a multicenter, cohort study. Am J Gastroenterol 2003;98:6539.

27. Pauwels A, Fourdan O, Carbonell N. Mortality from digestive hemorrhage for the last fifteen years. Gastroenterol Clin Biol 1998;22:A27.

28. Ismail F, Mumtaz $\mathrm{K}$, Shah $\mathrm{H}$, et al. Factors predicting in-hospital mortality in patients with cirrhosis hospitalized with gastro-esophageal variceal hemorrhage. Indian J Gastroenterol 2006;25:240-3.

29. Carbonell N, Pauwels A, Serfaty L, et al. Improved survival after variceal bleeding in patients with cirrhosis over the past two decades. Hepatol 2004;40:652-9.

30. Lyles T, Elliott A, Rockey D. A risk scoring system to predict in-hospital mortality in patients with cirrhosis presenting with upper gastrointestinal bleeding. J Clin Gastroenterol 2014;48:712-20.

31. Morales Uribe $\mathrm{CH}$, Sierra Sierra S, Hernández Hernández AM, et al. Upper gastrointestinal bleeding: risk factors for mortality in two urban centres in Latin America. Rev Esp Enferm Dig 2011;103:20-4.

32. Management of acute upper and lower gastrointestinal bleeding. A national clinical guideline. Edinburgh, UK: Scottish Intercollegiate Guidelines Network Elliott House; 2008. Available from: http://www.sign.ac.uk/pdf/ sign105.pdf

33. Acute upper gastrointestinal bleeding Management Clinical Guideline Methods, evidence and recommendations. London, UK: National Clinical Guideline Centre; 2012. Available from: https://www.nice.org.uk/guidance/cg141

34. Mega JL, Simon T. Pharmacology of antithrombotic drugs: an assessment of oral antiplatelet and anticoagulant treatments. Lancet 2015;386:281-91.

35. Qi X, Peng Y, Li H, et al. Diabetes is associated with an increased risk of inhospital mortality in liver cirrhosis with acute upper gastrointestinal bleeding. Eur J Gastroenterol Hepatol 2015;27:476-7.

36. Bianchi G, Marchesini G, Zoli M, et al. Prognostic significance of diabetes in patients with cirrhosis. Hepatology 1994;20:119-25.

37. Moreau R, Chagneau C, Heller J, et al. Hemodynamic, metabolic and hormonal responses to oral glibenclamide in patients with cirrhosis receiving glucose.
Scand J Gastroenterol 2001;36:303-8.

38. Majid S, Zahid Azam Z, Shah H, et al. Factors determining the clinical outcome of acute variceal bleedin cirrhotic patients. Indian J Gastroenterol 2009; 28:93-5.

39. Huang YW, Yang SS, Fu SC, et al. Increased risk of cirrhosis and its decompensation in chronic hepatitis $\mathrm{C}$ patients with new-onset diabetes: a nationwide cohort study. Hepatology 2014;60:80714.

40. Soma J, Saito T, Taguma Y, et al. High prevalence and adverse effect of hepatitis $\mathrm{C}$ virus infection in type II diabetic-related nephropathy. J Am Soc Nephrol 2000;11:690-9.

41. Hedges SJ, Dehoney SB, Hooper JS, et al. Evidence-based treatment recommendations for uremic bleeding. Nat Clin Pract Nephrol 2007;3:138-53.

42. Kalman RS, Pedrosa MC. Evidencebased review of gastrointestinal bleeding in the chronic kidney disease patient. Semin Dial 2015;28:68-74.

43. Anand D, Gupta R, Dhar M, Ahuja V. Clinical and endoscopic profile of patients with upper gastrointestinal bleeding at tertiary care center of North India. J Dig Endosc 2014;5:139-43.

44. Al-Freah M, Gera A, Martini S, et al. Comparison of scoring systems and outcome of patients admitted to a liver intensive care unit of a tertiary referral center with severe variceal bleeding. Aliment Pharmacol Ther 2014;39:1286-300.

45. Peng Y, Qi X, Dai J, et al. CTP versus MELD score for predicting the in-hospital mortality of acute upper gastrointestinal bleeding in liver cirrhosis. Int J Clin Exp Med 2015;8:751-7.

46. Sempere L, Palazon M, Sanchez-Paya J, et al. Assessing the short-and long-term prognosis of patients with cirrhosis and acute variceal bleeding. Rev Esp Enferm Dig 2009;101:236-48.

47. Nakamura S, Matsumoto T, Sugimori H, et al. Emergency endoscopy for acute gastrointestinal bleeding: prognostic value of endoscopic hemostasis and the AIMS65 score in Japanese patients. Dig Endosc 2014;26:369-76.

48. Hyett BH, Abougergi MS, Charpentier JP, et al. The AIMS65 score compared with the Glasgow-Blatchford score in predicting outcomes in upper GI bleeding. Gastrointest Endosc 2013;77:5517.

49. Tandon P, Abraldes JG, Keough A, et al. Risk of bacterial infection in patients with cirrhosis and acute variceal hemorrhage, based on Child-Pugh class, and effects of antibiotics. Clin Gastroenterol Hepatol 2015;13:1189-96. 